\title{
Activity of Pontine Neurons during Sleep and Cataplexy in Hypocretin Knock-Out Mice
}

\author{
Stephen Thankachan, Satvinder Kaur, and Priyattam J. Shiromani \\ West Roxbury Veterans Administration Medical Center and Harvard Medical School, West Roxbury, Massachusetts 02132
}

\begin{abstract}
Narcolepsy is a human sleep disorder resulting from the loss of neurons containing the neuropeptide orexin, also known as hypocretin. Cataplexy, which is a sudden loss of muscle tone during waking, is an important diagnostic symptom of narcolepsy. In humans and canines with narcolepsy, cataplexy is considered to be a separate and distinct behavioral state. However, in the mouse model of the disease this issue is not resolved. The present study monitored the activity of forty four neurons in the rostral pons in hypocretin knock-out mice. Majority of the neurons were active during wake and REM sleep, while four neurons were selectively active during REM sleep. All of these neurons were less active during cataplexy compared with REM sleep. Thus, although cataplexy and REM sleep share many common features, including the muscle atonia, cataplexy is a distinct state in mice.
\end{abstract}

Key words: REM; brainstem; knock-out mice; extracellular recordings; periaqueductal gray; peptide

\section{Introduction}

Narcolepsy is now considered to be a neurodegenerative sleep disorder linked to the loss of neurons containing the neuropeptide orexin, also named hypocretin (HCRT) (Peyron et al., 2000; Thannickal et al., 2000). However, canine narcolepsy results from a mutation of the hypocretin-2 receptor (Lin et al., 1999) without any discernible loss of the HCRT neurons. In rodents, narcoleptic symptoms are triggered in response to deletion of the HCRT gene (Chemelli et al., 1999), loss of neurons bearing the gene (Gerashchenko et al., 2001; Hara et al., 2001), or deletion of the hypocretin-2 receptor (Willie et al., 2003).

Cataplexy, which is defined as a sudden loss of antigravity muscles during waking, is an important diagnostic symptom of the disease. In humans and canines with narcolepsy, the attack is usually triggered by strong positive emotions such as laughter (humans), play (both humans and canines), or food (canines) (Siegel and Boehmer, 2006). In rats and mice, positive emotions may also be the trigger, and the attacks can be identified because the rodents abruptly stop moving during waking. During a cataplectic attack, humans and canines are usually conscious and aware of their surroundings (Siegel and Boehmer, 2006). Indeed, during such episodes in canines with narcolepsy, the histaminergic neurons are as active as in waking, and the canines are fully awake and aware of their surroundings (John et al., 2004). During sleep, even rapid-eye movement sleep (REM sleep), these neurons are silent (John et al., 2004; Wu et al., 2004). This indicates that the cataplectic state in humans and canines is separate and

Received 0ct. 24, 2008; revised Dec. 11, 2008; accepted Jan. 6, 2009.

This work was supported in part by the Department of Veterans Affairs, Veterans Health Administration, Office of Research Development (BLR\&D), and National Institutes of Health Grants NS030140 and NS052287. We are grateful to Dr. Carlos Blanco-Centurion for helpful discussions and Suraiya Begum for expert technical assistance.

Correspondence should be addressed to Priyattam J. Shiromani, West Roxbury Veterans Administration Medical Center, 1400 Veterans of Foreign Wars Parkway, West Roxbury, MA 02132. E-mail: pshiromani@hms.harvard.edu. D01:10.1523/JNEUROSCI.5151-08.2009

Copyright $\odot 2009$ Society for Neuroscience $\quad$ 0270-6474/09/291580-06\$15.00/0 distinct from REM sleep or non-REM sleep. However, in rodents it is not known if such attacks represent quick transitions into REM sleep since all of the cardinal signs of REM sleep are also present during these attacks. Mice, in which the HCRT gene has been genetically deleted (HCRT knock-out), provide an excellent model system to study the underlying neurobiology of cataplexy and REM sleep. The present study monitored the activity of individual neurons in the rostral pons, and we find that as in humans and canines with narcolepsy, the cataplectic state in HCRT-ko mice is separate and distinct from REM sleep.

\section{Materials and Methods}

HCRT knock-out mice (HCRT-ko; 3-7 months old; 20-35 g) were bred in our facility. Only mice homozygous with respect to the deletion of the HCRT gene were used (identified by PCR of tail snips) as heterozygotes do not have narcoleptic behavior (Chemelli et al., 1999). These experiments were conducted in accordance with the guidelines established by the National Institutes of Health, and the research protocol was approved by the West Roxbury Veterans Administration Medical Center's institutional animal care and use committee (IACUC).

\section{Surgical procedures}

The HCRT-ko mice were implanted under anesthesia (2\% isofluorane, continuous) with electrodes to record the electroencephalogram (EEG) and electromyogram (EMG) as described previously (Shiromani et al., 2004). Four stainless steel screw electrodes positioned in the skull to sit on the surface of the cortex recorded the EEG (two in the frontal cortex and two in the parietal cortex), and two flexible multistranded wires placed in the nuchal muscles recorded the muscle activity (EMG). The electrodes were inserted into a socket and secured onto the skull using dental cement.

In addition, the mice were also implanted with a miniature microdrive (McGinty and Harper, 1976; Thankachan et al., 2001) that was secured onto the skull using dental cement. The microdrive consisted of an outer cannula (22 g; stainless steel) secured to a nut-screw-spring assembly. An inner cannula ( $26 \mathrm{~g}$ ) was inserted into the outer cannula and positioned $1.5 \mathrm{~mm}$ above the ventrolateral periaquaductal gray (vlPAG) (anteroposterior $-5.0 \mathrm{~mm}$, lateral $0.8 \mathrm{~mm}$, dorsoventral $2.8-3.2 \mathrm{~mm}$ ) (Franklin 
A
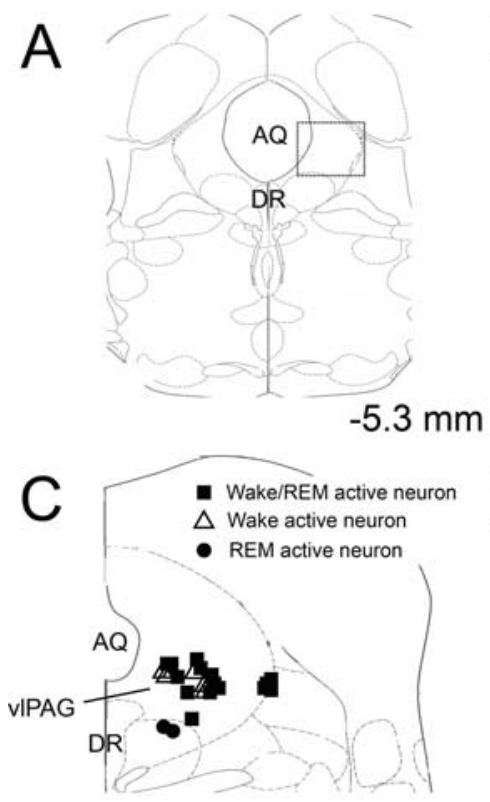

$-5.1 \mathrm{~mm}$
B

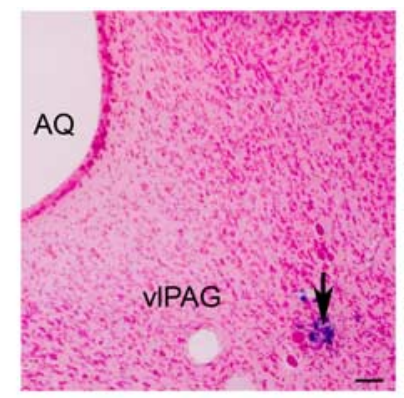

\section{$\mathrm{D}$}

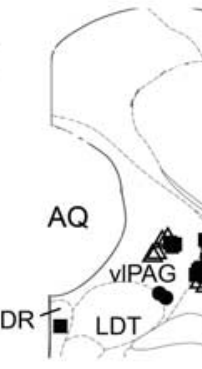

$-5.3 \mathrm{~mm}$

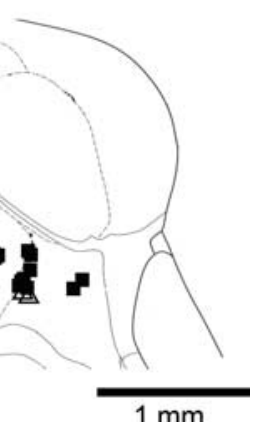

$1 \mathrm{~mm}$

Figure 1. Schematic illustration of the region of the brain where neurons were recorded in hypocretin knock-out mice. $A$ provides an overall view of the location of the region of interest (Franklin and Paxinos, 1997). $\boldsymbol{B}$ is a photomicrograph of a Nisslstained tissue section (neutral red) from a representative hypocretin knock-out mice with the microwire tip marked by Perl's Prussian blue staining (arrow). $\boldsymbol{C}$ and $\boldsymbol{D}$ schematically depict the location of recorded neurons. The four REM sleep active neurons bordered the LDT. AQ, Aqueduct; DR, dorsal raphe; LDT, laterodorsal tegmentum; vIPAG, ventrolateral periaqueductal gray. Scale bar: $\boldsymbol{B}, 100 \mu \mathrm{m}$.

and Paxinos, 1997). Six $25 \mu \mathrm{m}$ microwires (formvar coated; AM Systems) soldered at one end to a gold-plated connector and bevel-cut at the other end were inserted through the internal cannula. The bevel-cut end of the wires extended $1.5 \mathrm{~mm}$ from the tip of the inner cannula. The entire bundle of wires was protected by SILASTIC tubing (Bentec Medical) and could be moved up and down by turning the screw.

One day after the surgery, the animals were connected to light weight recording cables. After a 2 week period of adaptation and recovery from the effects of surgery, sleep and neuronal activity were recorded.

\section{Recording of sleep-wake states and unit recording}

Sleep recording. The EEG was recorded from two contralateral screws (frontal-occipital). The EEG and EMG signals were recorded to a computer with SciWork software (DataWave Technologies). The animals were housed singly in Plexiglas cages with wood shavings, and food and water were available ad libitum. The temperature in the sleep recording room was $25^{\circ} \mathrm{C}$, and a $12 / 12 \mathrm{~h}$ light/dark cycle (7:00 A.M. to 7:00 P.M. lights-on; 100 lux) was maintained.

Identification of episodes of cataplexy. The EEG and EMG recordings together with night vision video recordings identified cataplexy. Neurons were recorded during the first half of the dark cycle when the incidence of cataplexy is high in narcoleptic rodents. The following criteria were used: an abrupt loss of muscle tone during wake lasting at least $20 \mathrm{~s}$; the mouse was immobile during the episode; theta activity $(4-8 \mathrm{~Hz})$ dominated the EEG during the episode; and at least $40 \mathrm{~s}$ of wakefulness preceded the episode. A consensus agreement has been reached that when EEG, EMG and video recordings are used such episodes represent murine cataplexy (Scammell et al., 2009).

Recording of single neuronal activity. Extracellularly recorded action potentials (signal-to-noise $>3: 1$ ) were amplified $(10,000 \times)$ ), filtered (bandpass $300 \mathrm{~Hz}$ to $10 \mathrm{kHz}$ ), digitized ( $30 \mathrm{kHz}$, DT304 Data Translation board; DataWave Technologies) and recorded using SciWorks software (DataWave Technologies) on a computer. The action potentials ("spikes") of a single neuron were identified with DataWave's autosort cluster analysis. Briefly, spike waveform attributes were extracted from each triggered spike and plotted on $x-y$ scatterplots. Spikes with similar attributes formed clusters. To confirm the accurate boundaries of these clusters and to remove any remaining artifacts, spike waveforms were visually inspected, and sorted into action potentials of single neurons.

Location of recording electrodes. After completing the full dorsal-ventral extension of the microdrive, the mice were anesthetized (overdose of Nembutal), and an anodal current (1 $\mathrm{mA}$ for $30 \mathrm{~s}$ ) was applied to each electrode that recorded neurons to deposit iron and mark the target area. The animal was then transcardially perfused with saline and $4 \%$ phosphatebuffered formalin. The brain was sectioned and the ferrous deposit (Perl's Prussian blue staining) identified by microscopy.

Classification of neurons based on their discharge rate during sleep-wake and cataplexy. Neuronal activity was determined in a $20 \mathrm{~s} \mathrm{ep}$ och during wake, non-REM and REM sleep and during cataplexy. To clearly demarcate cataplexy and REM sleep we took the neuronal discharge during the $20 \mathrm{~s}$ epoch before the end of these episodes. This period was analyzed because in the HCRT-ko mice it is difficult to accurately identify when cataplexy begins, although the end of the bout is clear since the mouse wakes up and is active (muscle tone is high). Similarly, in mice, as in all mammals, it is not obvious when REM sleep begins, but the end of the REM sleep bout is unambiguous. Therefore, in the present study, peristimulus/ event time histograms (PSTH) were generated for the epochs during the transition points between cataplexy and wake, and REM sleep and wake. The abrupt change in the muscle activity during the transition points marked the stimulus or event for these PSTH.

Neuronal activity was assessed in $20 \mathrm{~s}$ epochs during active waking, middle of the non-REM sleep period, end of REM sleep and end of cataplexy. At least five epochs were derived from these states. Based on the mean neuronal discharge rate the neurons were categorized into five groups: (1) Wake/REM active fast firing $(2.1-7.5 \mathrm{~Hz})$; (2) Wake/REM active slow firing $(0-2 \mathrm{~Hz})$; (3) Wake active fast firing $(2.1-5 \mathrm{~Hz})$; (4) Wake active slow firing $(0-2 \mathrm{~Hz})$; and (5) REM active neurons. The neuronal activity between the various states was compared statistically using a repeated measures one-way ANOVA, followed by the HolmSidak post hoc test.

\section{Results}

Forty-four neurons were recorded from the rostral pons that included the vlPAG, and some portions of the dorsal raphe, and laterodorsal tegmental areas (Fig. 1). The neurons were recorded from 11 HCRT-ko mice, and only those neurons that were recorded during at least five alternation of the sleep-wake cycle (wake, non-REM and REM sleep state) and cataplexy are reported here. Neuronal activity was recorded for $7-8 \mathrm{~h}$ and the difficulty of maintaining units was no different from our experience with rats and cats.

\section{Group I and II: wake/REM active neurons}

Twenty-eight of 44 neurons (63.6\%) had higher activity during wake and REM sleep compared with non-REM sleep (Fig. $2 A, C$ ). These wake/REM active neurons were typical of neurons recorded in the brainstem (Siegel et al., 1981). Figure 3 shows neuronal activity of one such neuron. Based on the basal firing rate during waking 16 neurons were classified as "fast firing" $(>2.1$ spikes/s) (Fig. $2 A)$, while the remaining neurons $(n=12)$ were 
A
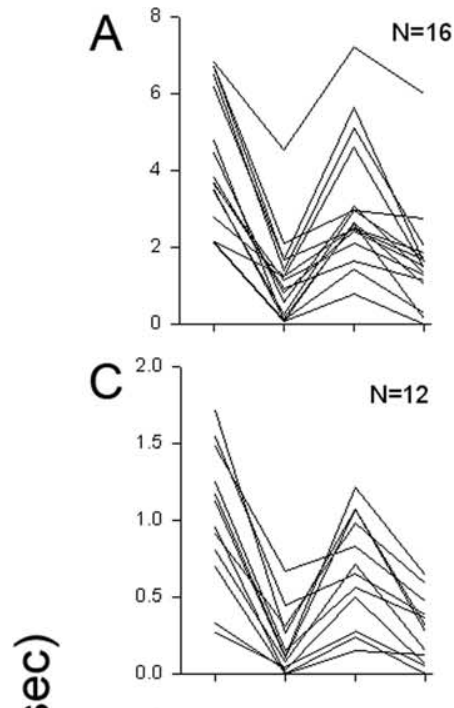

$\left.E^{5}\right] \quad \mathrm{N}=6$
क्ञ

$\stackrel{\oplus}{\stackrel{0}{*}}$

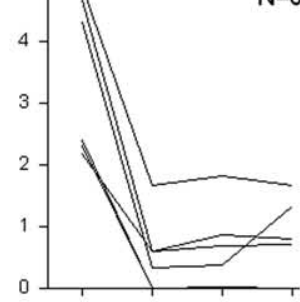

읃

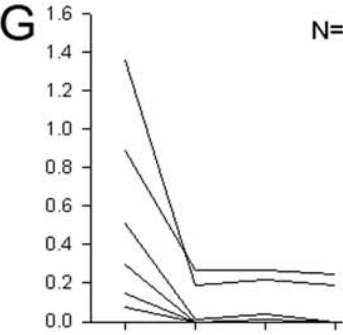

I

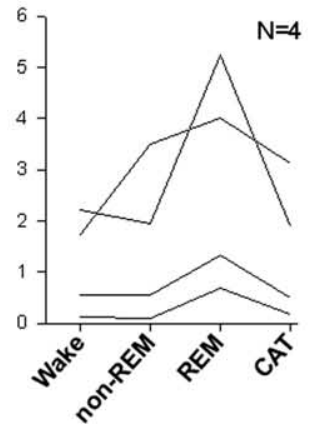

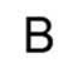

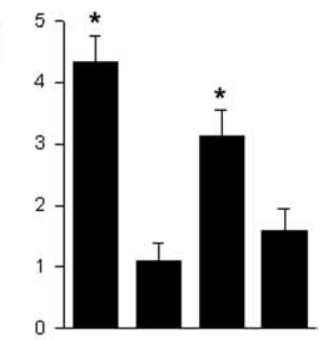

D

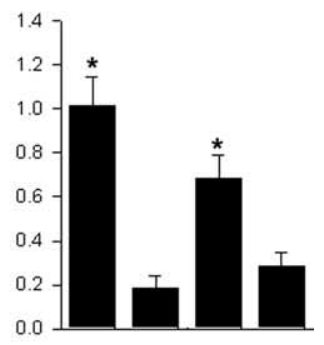

$\mathrm{F}$

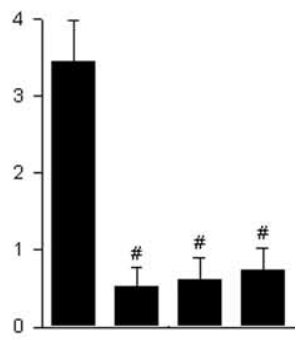

$\mathrm{H}$

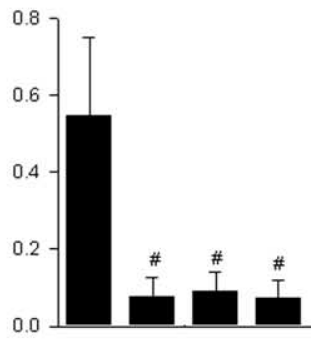

$\mathrm{J}$

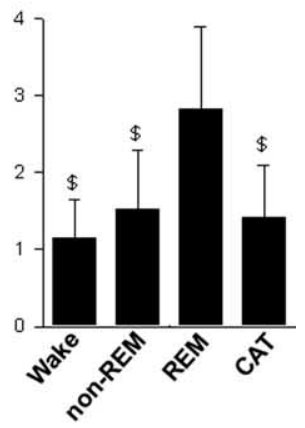

Figure 2. Discharge patterns [firing rate (spikes/s)] of 44 neurons recorded from the pons during wake, non-REM, REM sleep, and cataplexy (CAT). The figures in the left panel summarize the activity of all 44 recorded neurons while the bar graphs summarize the mean ( \pm SEM) discharge rate during the four behavioral states. ${ }^{*} p<0.01$ versus non-REM sleep; ${ }^{*} p<0.01$ versus wake; $\$ p<0.03$ versus REM sleep.

classified as "slow firing" (0-2 spikes/s) (Fig. 2C). Regardless of whether these neurons were slow or fast firing they were more active during waking and REM sleep compared with non-REM sleep (Fig. $2 B, D$ ). Mean firing rate for the fast firing neurons during wake and REM sleep were $4.32 \pm 0.43$ and $3.11 \pm 0.42$ spikes/s, respectively, compared with non-REM sleep which was $1.11 \pm 0.28$ spikes/s (Fig. $2 B$ ). The slow firing neurons had a

mean firing rate of $1.01 \pm 0.13$ and $0.68 \pm 0.1$ spikes/s during wake and REM sleep, respectively, while during non-REM sleep the mean firing rate was $0.18 \pm 0.05$ spikes/s (Fig. 2D). Both the fast and the slow firing neurons were significantly more active during wake (fast: $t=10.17 ; p<0.01$; slow: $t=9.06, p<0.01$ ) and REM sleep (fast: $t=6.35 ; p<0.01$; slow: $t=5.47 ; p<0.01$ ) compared with non-REM sleep.

\section{Groups III and IV: wake active neurons}

12 of $44(27.3 \%)$ neurons were more active during waking compared with non-REM and REM sleep (Fig. 2E, G). All of these 12 neurons showed no significant change in firing between nonREM and REM sleep state. Six of these neurons were fast $(>2.1$ spikes/s) (Fig. $2 E$ ) while the other six neurons were slow $(0-2$ spikes/s) (Fig. 2G). The fast firing neurons had a mean of $3.45 \pm$ 0.52 spikes/s during wake and it was significantly higher compared with non-REM $(0.52 \pm 0.24$ spikes/s; $t=10.19 ; p<0.01$; post hoc) and REM sleep $(0.61 \pm 0.27$ spikes $/$; $t=9.85 ; p<0.01$; post hoc) (Fig. $2 F$ ). The mean rate for the slow firing neurons during wake was $0.54 \pm 0.2$ spikes/s and it was significantly higher compared with non-REM $(0.07 \pm 0.04$ spikes $/ \mathrm{s} ; t=4.08$; $p<0.01$; post hoc $)$ and REM sleep $(0.09 \pm 0.04$ spikes/s; $t=3.98$; $p<0.01$; post hoc) (Fig. $2 \mathrm{H}$ ).

\section{Group V: REM active neurons}

Four of 44 (9\%) neurons were more active during REM sleep compared with wake and non-REM sleep (Fig. $2 I$ ). One such REM active neuron is shown in Figure 4. The mean firing rate of neurons during REM sleep was $2.81 \pm 1.08$ spikes/s and was significantly higher compared with wake $(1.15 \pm 0.48$ spikes/s; $t=3.19 ; p<0.01$; post hoc $)$ and non-REM sleep $(1.52 \pm 0.7$ spikes/s; $t=2.49 ; p<0.03$; post hoc) (Fig. $2 J$ ).

Group I and II: wake/REM active neurons during cataplexy Neuronal activity during sleep-wake states was compared with cataplexy. Both the slow and fast firing neurons were grouped together. Twenty-six of 28 (92\%) of wake/REM active neurons had a significant decrease in discharge rate during cataplexy (Fig. $2 A, B$ ), while the remaining two showed no change. Figure $3 A-C$ represents one such neuron that was more active during wake and REM sleep compared with non-REM sleep. A rate histogram determined that the activity of this neuron was similar during waking and REM sleep (Fig. $3 E, F$ ), but during a cataplexy episode this neuron decreased activity compared with the wake state (Fig. 3D). A peristimulus/event time histogram of firing just before and after cataplexy shows that this neuron changed its activity from low to high upon termination of cataplexy (Fig. $3 G$ ). However, this wake/REM active neuron did not significantly change its activity as it transited from REM sleep to wake (Fig $3 H)$.

Group III and IV: wake active neurons during cataplexy

All of the wake active neurons $(n=12)$, regardless of whether they were fast or slow firing were less active during cataplexy (Fig. $2 E-H)$. This indicates that the activity of these neurons was not associated with a desynchronized EEG which is seen during both waking and cataplexy.

\section{Group V: REM active neurons during cataplexy}

Four neurons were REM active relative to waking and non-REM sleep. All of these REM active neurons decreased firing during cataplexy. A representative REM active neuron is depicted in Figure 4 . The rate histogram shows that this neuron was more 
Wake

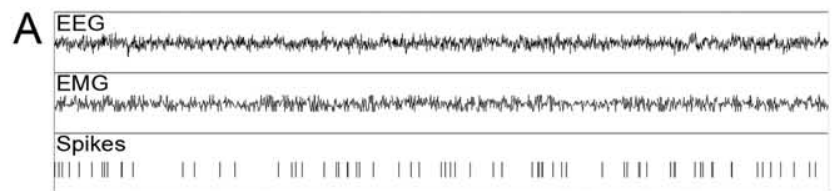

REM sleep

C
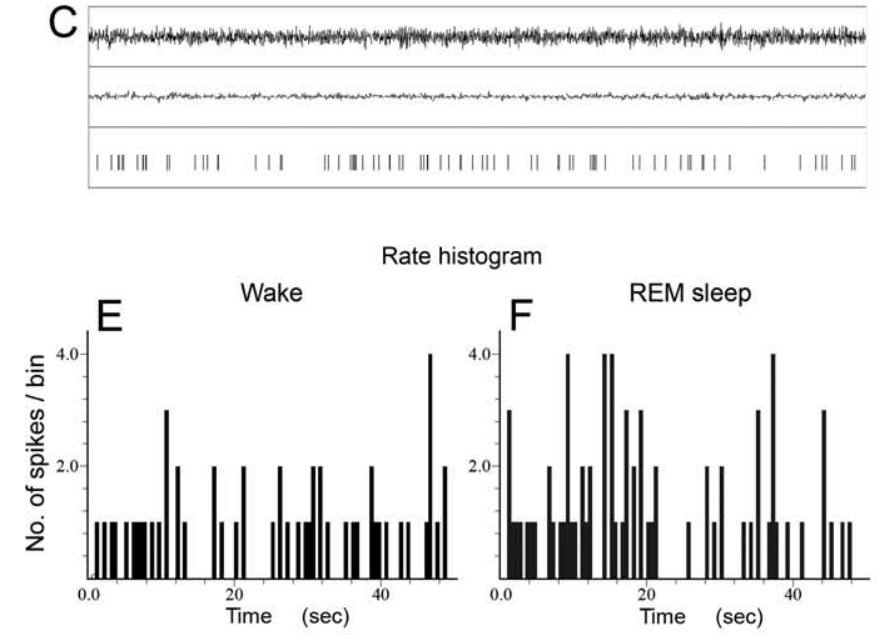

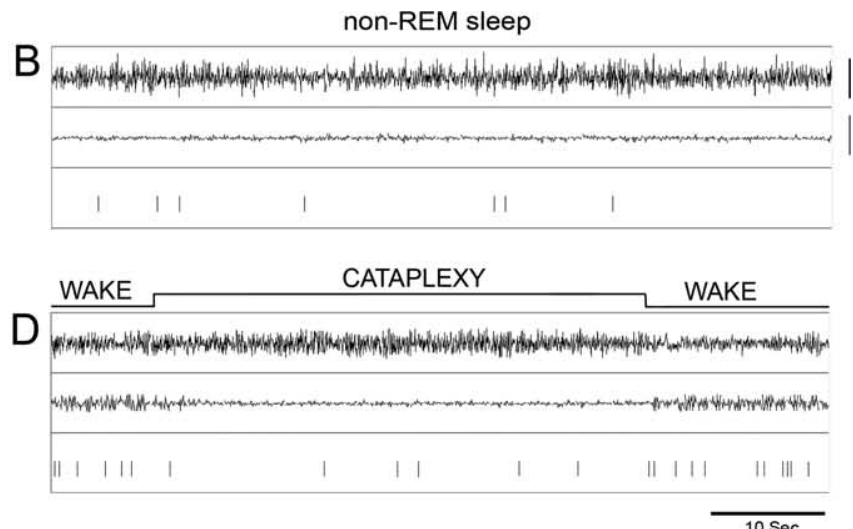

Peri-stimulus/event time histogram

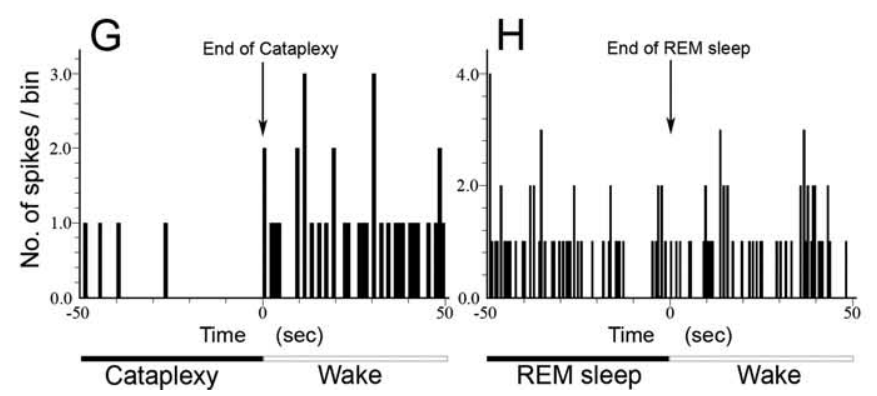

Figure 3. Activity of a representative single wake/REM sleep active neuron across various sleep-wake behaviors. $\boldsymbol{A}-\boldsymbol{D}$, The activity of the same neuron is depicted during wake $(\boldsymbol{A})$, non-REM sleep $(\boldsymbol{B})$, REM sleep $(\boldsymbol{C})$, and cataplexy $(\boldsymbol{D}) . \boldsymbol{E}, \boldsymbol{F}$, Rate histograms summarizes the discharge rate (number of spikes/bin; bin width $=500 \mathrm{~ms}$ ) during wake $(\boldsymbol{E})$ and REM sleep $(\boldsymbol{F})$ and demonstrates that this neuron was active during both wake and REM sleep. $\mathbf{G}, \boldsymbol{H}$, Peristimulus/event time histogram summarizes the change in discharge rate (spikes/bin; bin width $=500$ ms) of this neuron during transition from cataplexy to wake $(\boldsymbol{G})$ and from REM sleep to waking $(\boldsymbol{H})$. As can be seen in $\boldsymbol{G}$ and $\boldsymbol{H}$, this neuron increased firing from cataplexy (no muscle tone) to waking, but its activity did not change from REM sleep (no muscle tone) to wake. Calibration: $100 \mu \mathrm{V}$.

Wake

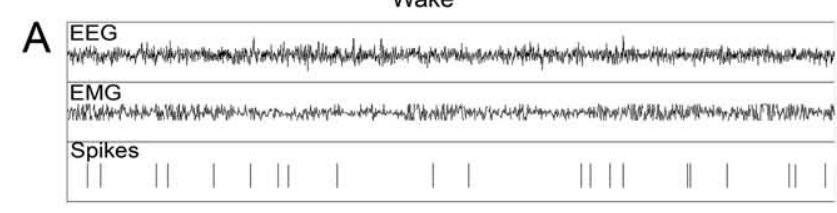

REM sleep
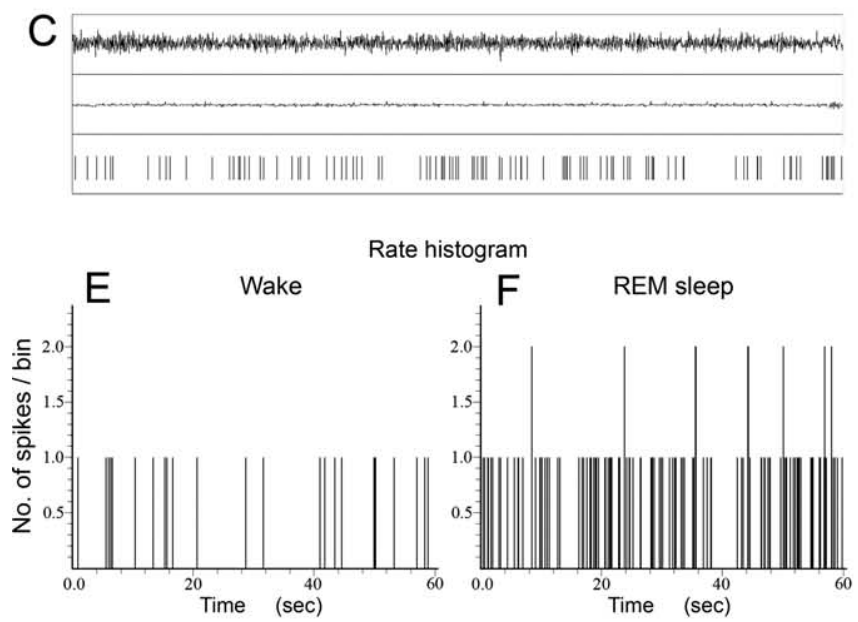

non-REM sleep
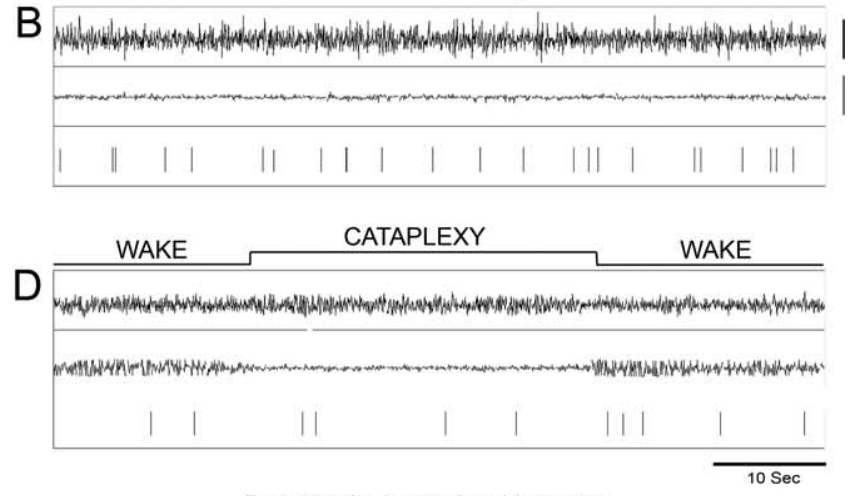

Peri-stimulus/event time histogram

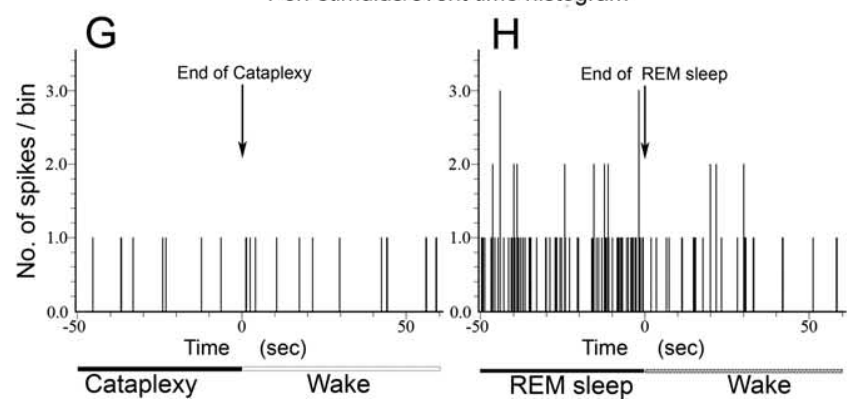

Figure 4. Activity of a representative REM sleep active neuron across sleep-wake behaviors. $\boldsymbol{A}-\boldsymbol{D}$, The activity of the same neuron is depicted during wake $(\boldsymbol{A})$, non-REM sleep ( $\boldsymbol{B})$, REM sleep ( $\boldsymbol{C}$ ) and cataplexy $(\boldsymbol{D}) . \boldsymbol{E}, \boldsymbol{F}$, Rate histograms summarizes the discharge rate (number of spikes/bin; bin width $=100 \mathrm{~ms}$ ) during wake $(\boldsymbol{E})$ and REM sleep $(\boldsymbol{F})$ and demonstrates that this neuron was more active during REM sleep compared with wake. $\mathbf{G}, \boldsymbol{H}$, Peristimulus/event time histogram summarizes the change in discharge rate (spikes/bin; bin width $=100 \mathrm{~ms}$ ) of this neuron during transition from cataplexy to wake $(\boldsymbol{G})$ and from REM sleep to waking $(\boldsymbol{H})$. As can be seen in $\boldsymbol{G}$ and $\boldsymbol{H}$, this neuron's activity did not change from cataplexy (no muscle tone) to waking, but it decreased firing from REM sleep (no muscle tone) to wake. Calibration: $100 \mu \mathrm{V}$. 
active in REM sleep (Fig. 4F) compared with waking (Fig. 4E). A peristimulus/event time histogram (Fig. 4G) reveals that the discharge rate of this neuron did not change as it transited from cataplexy (no muscle tone) to waking (high muscle tone). Nevertheless, the same neuron changed its firing rate from a higher discharge during REM sleep (no muscle tone) to a lower discharge rate upon entering wake (high muscle tone) (Fig. 4H).

\section{Discussion}

This is the first study to monitor the activity of single neurons in freely behaving HCRT-ko mice. The microwire method used in the present study has been used previously to monitor neuronal activity in canines with narcolepsy (John et al., 2004; Wu et al., 2004). The advantage of this method is that it allows the animal to engage in its full repertoire of behavior. The animal's behavior is especially critical for this study as individual bouts of cataplexy need to be easily and clearly evident.

There are similarities between cataplexy and REM sleep in the HCRT-ko mice. In both states muscle tone is absent, behaviorally the animal is immobile, and the EEG predominantly oscillates in the theta frequency $(4-8 \mathrm{~Hz})$ but may contain a mixture of slow (1-4 Hz) waves also. Thus, at least on the basis of the EEG and behavior it is difficult to ascertain whether in the HCRT-ko mice the episodes of cataplexy actually represent inappropriate intrusions of REM sleep into the waking state. Therefore, the underlying neuronal activity in a region important for both states was monitored and from the results we conclude that cataplexy is a distinct state in the HCRT knock-out mice separate from wake, non-REM sleep and REM sleep.

Most of the neurons (40 of 44) were wake-active or wakeREM active. Four neurons (4 of 44) were active during REM sleep. These REM-on neurons bordered the lateral dorsal tegmental (LDT) area where REM-on neurons have been recorded in cats (Steriade et al., 1990). The activity of the recorded neurons did not anticipate the beginning or end of cataplexy. There were no neurons that were active during non-REM sleep or cataplexy. There are numerous reports on the activity of brainstem neurons across sleep-wake states, especially in the cat (Siegel et al., 1981). However, it is only recently that the activity of neurons in the rostral pontine area, in particular the vlPAG has been studied. We found the range of neuronal activity including REM sleep active neurons that have been found in rats (Kayama et al., 1992) and cats (Thakkar et al., 2002). Moreover, the activity of the recorded neurons in mice was similar to that reported previously (Kayama et al., 1992; Thakkar et al., 2002).

In the present study, neuronal activity in the rostral pons was sampled because of emerging evidence that activation of neurons in this region during wake might inhibit REM sleep and cataplexy (Luppi et al., 2006). In the present study, 27\% (12 of 44) of neurons were wake-active compared with non-REM, REM sleep or cataplexy (Fig. $2 E-H$ ). These neurons may be GABAergic and their activity during waking may inhibit REM sleep as proposed (Luppi et al., 2006). It is not known whether these GABA neurons also inhibit cataplexy. The limbic system, in particular the amygdala, is likely to play an important role in cataplexy, since cataplexy is generally triggered in response to emotion. Neurons that are activated during cataplexy in canines have been found in the amygdala (Gulyani et al., 2002). These neurons may then converge onto pontine and medullary neurons which then inhibit gamma-motor neurons in the spinal cord (Kodama et al., 2003; Brooks and Peever, 2008).

How do these data compare with the canine model of narcolepsy? Canines with narcolepsy were the first animal model of the disorder. As a result, neuronal activity has been recorded in many brain regions using the same methodology as in the present study. In the canine model, as in the present study, the majority of neurons in the rostral pontine region (Siegel et al., 1992) were wake-active or wake-REM active, and as in the present study these neurons were not very active during cataplexy (Siegel et al., 1992). In other regions, such as the tuberomammillary nucleus the neurons were found to be active in cataplexy but silent during REM sleep (John et al., 2004). In the locus ceruleus and dorsal raphe, neurons were silent in cataplexy just as in REM sleep (Wu et al., 1999, 2004). However, in the medial medulla, which may represent the final common pathway for muscle atonia, neurons were active in REM sleep and cataplexy (Siegel et al., 1991). It is important to gather more data in murine cataplexy, since such studies will provide generality of the findings between murine and canine narcolepsy, and clarify the network underlying cataplexy.

In humans (Peyron et al., 2000; Thannickal et al., 2000), canines (Lin et al., 1999) and rodents, HCRT or the HCRT-2 receptor is an essential component of the circuit responsible for maintaining muscle tone. In all three, the symptoms of cataplexy are similar with the attacks occurring abruptly during waking. Muscle tone is absent during both cataplexy and REM sleep. However, the loss of muscle tone in REM sleep is a natural process occurring during sleep in virtually all mammals and birds. In contrast, in cataplexy muscle atonia is abnormally triggered during wakefulness. Therefore, a therapeutic intervention should block cataplexy but not the muscle atonia of REM sleep. Otherwise the treatment risks creating another sleep disorder, REM sleep behavior disorder (Schenck and Mahowald, 1992). It is important to distinguish between cataplexy and REM sleep so that the neurobiology of each state can be better understood and defined. Once the network is better defined, pharmacotherapy or even gene therapy (Liu et al., 2008) can be used to repair the network.

\section{References}

Brooks PL, Peever JH (2008) Glycinergic and $\mathrm{GABA}_{\mathrm{A}}$-mediated inhibition of somatic motoneurons does not mediate rapid eye movement sleep motor atonia. J Neurosci 28:3535-3545.

Chemelli RM, Willie JT, Sinton CM, Elmquist JK, Scammell T, Lee C, Richardson JA, Williams SC, Xiong Y, Kisanuki Y, Fitch TE, Nakazato M, Hammer RE, Saper CB, Yanagisawa M (1999) Narcolepsy in orexin knockout mice: molecular genetics of sleep regulation. Cell 98:437-451.

Franklin KBJ, Paxinos G (1997) The mouse brain in stereotaxic coordinates. San Diego: Academic.

Gerashchenko D, Kohls MD, Greco M, Waleh NS, Salin-Pascual R, Kilduff TS, Lappi DA, Shiromani PJ (2001) Hypocretin-2-saporin lesions of the lateral hypothalamus produce narcoleptic-like sleep behavior in the rat. J Neurosci 21:7273-7283.

Gulyani S, Wu MF, Nienhuis R, John J, Siegel JM (2002) Cataplexy-related neurons in the amygdala of the narcoleptic dog. Neuroscience 112:355-365.

Hara J, Beuckmann CT, Nambu T, Willie JT, Chemelli RM, Sinton CM, Sugiyama F, Yagami K, Goto K, Yanagisawa M, Sakurai T (2001) Genetic ablation of orexin neurons in mice results in narcolepsy, hypophagia, and obesity. Neuron 30:345-354.

John J, Wu MF, Boehmer LN, Siegel JM (2004) Cataplexy-active neurons in the hypothalamus: implications for the role of histamine in sleep and waking behavior. Neuron 42:619-634.

Kayama Y, Ohta M, Jodo E (1992) Firing of 'possibly' cholinergic neurons in the rat laterodorsal tegmental nucleus during sleep and wakefulness. Brain Res 569:210-220.

Kodama T, Lai YY, Siegel JM (2003) Changes in inhibitory amino acid release linked to pontine-induced atonia: an in vivo microdialysis study. J Neurosci 23:1548-1554.

Lin L, Faraco J, Li R, Kadotani H, Rogers W, Lin X, Qiu X, de Jong PJ, Nishino 
S, Mignot E (1999) The sleep disorder canine narcolepsy is caused by a mutation in the hypocretin (orexin) receptor 2 gene. Cell 98:365-376.

Liu M, Thankachan S, Kaur S, Begum S, Blanco-Centurion C, Sakurai T, Yanagisawa M, Neve R, Shiromani PJ (2008) Orexin (hypocretin) gene transfer diminishes narcoleptic sleep behavior in mice. Eur J Neurosci 28:1382-1393.

Luppi PH, Gervasoni D, Verret L, Goutagny R, Peyron C, Salvert D, Leger L, Fort P (2006) Paradoxical (REM) sleep genesis: the switch from an aminergic-cholinergic to a GABAergic-glutamatergic hypothesis. J Physiol Paris 100:271-283.

McGinty DJ, Harper RM (1976) Dorsal raphe neurons: depression of firing during sleep in cats. Brain Res 101:569-575.

Peyron C, Faraco J, Rogers W, Ripley B, Overeem S, Charnay Y, Nevsimalova S, Aldrich M, Reynolds D, Albin R, Li R, Hungs M, Pedrazzoli M, Padigaru M, Kucherlapati M, Fan J, Maki R, Lammers GJ, Bouras C, Kucherlapati R, Nishino S, Mignot E (2000) A mutation in a case of early onset narcolepsy and a generalized absence of hypocretin peptides in human narcoleptic brains. Nat Med 6:991-997.

Scammell TE, Willie JT, Guilleminault C, Siegel JM (2009) A consensus definition of cataplexy in mouse models of narcolepsy. Sleep 32:111-116.

Schenck CH, Mahowald MW (1992) Motor dyscontrol in narcolepsy: rapid-eye-movement (REM) sleep without atonia and REM sleep behavior disorder. Ann Neurol 32:3-10.

Shiromani PJ, Xu M, Winston EM, Shiromani SN, Gerashchenko D, Weaver DR (2004) Sleep rhythmicity and homeostasis in mice with targeted disruption of mPeriod genes. Am J Physiol Regul Integr Comp Physiol 287:R47-R57.

Siegel JM, Boehmer LN (2006) Narcolepsy and the hypocretin systemwhere motion meets emotion. Nat Clin Pract Neurol 2:548-556.

Siegel JM, Nienhuis R, Wheeler RL, McGinty DJ, Harper RM (1981) Discharge pattern of reticular formation unit pairs in waking and REM sleep. Exp Neurol 74:875-891.
Siegel JM, Nienhuis R, Fahringer HM, Paul R, Shiromani P, Dement WC, Mignot E, Chiu C (1991) Neuronal activity in narcolepsy: identification of cataplexy-related cells in the medial medulla. Science 252:13151318.

Siegel JM, Nienhuis R, Fahringer HM, Chiu C, Dement WC, Mignot E, Lufkin R (1992) Activity of medial mesopontine units during cataplexy and sleep-waking states in the narcoleptic dog. J Neurosci 12:1640-1646.

Steriade M, Datta S, Paré D, Oakson G, Curró Dossi RC (1990) Neuronal activities in brain-stem cholinergic nuclei related to tonic activation processes in thalamocortical systems. J Neurosci 10:2541-2559.

Thakkar MM, Strecker RE, McCarley RW (2002) Phasic but not tonic REMselective discharge of periaqueductal gray neurons in freely behaving animals: relevance to postulates of GABAergic inhibition of monoaminergic neurons. Brain Res 945:276-280.

Thankachan S, Islam F, Mallick BN (2001) Role of wake inducing brain stem area on rapid eye movement sleep regulation in freely moving cats. Brain Res Bull 55:43-49.

Thannickal TC, Moore RY, Nienhuis R, Ramanathan L, Gulyani S, Aldrich M, Cornford M, Siegel JM (2000) Reduced number of hypocretin neurons in human narcolepsy. Neuron 27:469-474.

Willie JT, Chemelli RM, Sinton CM, Tokita S, Williams SC, Kisanuki YY, Marcus JN, Lee C, Elmquist JK, Kohlmeier KA, Leonard CS, Richardson JA, Hammer RE, Yanagisawa M (2003) Distinct narcolepsy syndromes in Orexin receptor-2 and Orexin null mice: molecular genetic dissection of non-REM and REM sleep regulatory processes. Neuron 38:715-730.

Wu MF, Gulyani SA, Yau E, Mignot E, Phan B, Siegel JM (1999) Locus coeruleus neurons: cessation of activity during cataplexy. Neuroscience 91:1389-1399.

Wu MF, John J, Boehmer LN, Yau D, Nguyen GB, Siegel JM (2004) Activity of dorsal raphe cells across the sleep-waking cycle and during cataplexy in narcoleptic dogs. J Physiol 554:202-215. 